Haydarpasa Numune Med J 2018;58(4):227-228

\title{
Hydrocele of the Canal of Nuck in a Female: A Case Report
}

\author{
Duygu Demiriz Gülmez ${ }^{1}$, Mehmet Gülmez ${ }^{2}$ \\ ${ }^{1}$ Department of Anesthesiology, Opr. Dr. Ergun Ozdemir Gorele State Hospital, Giresun, Turkey \\ ${ }^{2}$ Department of General Surgery, Opr. Dr. Ergun Ozdemir Gorele State Hospital, Giresun, Turkey
}

\begin{abstract}
Hydrocele of the canal of Nuck is a very rare condition in females. A 30-year-old female presented to our clinic with a palpable mass in her right inguinal groin. Ultrasonographic findings were consistent with the diagnosis of a hydrocele of the canal of Nuck. Surgical resection of the hydrocele was performed, and histopathological examination of the surgical specimen confirmed the diagnosis.

Keywords: Hernia; hydrocele of the canal of nuck; processus vaginalis.
\end{abstract}

T he canal of Nuck is the patent embryological remnant of the processus vaginalis in females. It was first described by Anton Nuck a Dutch surgeon and anatomist in $1650^{[1]}$. Incomplete obliteration of the processus vaginalis causes indirect inguinal hernia or hydrocele of the canal of Nuck [2]. Hydrocele of the canal of Nuck is a very rare condition in females. Here, we report a case of hydrocele of the canal of Nuck, which was diagnosed with preoperative ultrasonography and treated with surgery.

\section{Case Report}

A 30-year-old female presented to our clinic with a palpable mass in her right inguinal groin, which was first noticed 4 months previously. There was no history of trauma, vomiting, abdominal pain, or change in bowel habits. Physical examination revealed an irreducible, translucent, and nontender swelling in the right inguinal region. The remaining physical examination was unremarkable. Ultrasonographic examination of the right inguinal region demonstrated an anechoic fluid-filled cystic structure measuring approximately $3 \mathrm{~cm} \times 2 \mathrm{~cm}$ in the right inguinal region. The diagnosis of hydrocele of the canal of Nuck was confirmed, and the patient underwent surgical exploration. A 3-cm, fluid-filled cystic structure was located under the fascia of external oblique muscle and dissected down to the labia majora (Fig. 1).

Histopathological examination of the cyst revealed that the interior surface of the cyst was covered with mesothelial cells and that the cyst wall comprised fibrous tissue, including smooth muscle fibers. The patient was discharged on postoperative day 2 with uneventful recovery period.

\section{Discussion}

The processus vaginalis, which is a homolog to the canal of Nuck in males, is usually obliterated after the seventh month of gestation. Although the exact process remains unclear, pathologies of the canal of Nuck are associated with incomplete obliteration. Incomplete obliteration of

Correspondence (iletişim): Mehmet Gülmez, M.D. Opr. Dr. Ergun Ozdemir Gorele Devlet Hastanesi, Genel Cerrahi Anabilim Dali, Giresun, Turkey Phone (Telefon): +90 5326566681 E-mail (E-posta): mehmetgulmez86@hotmail.com 


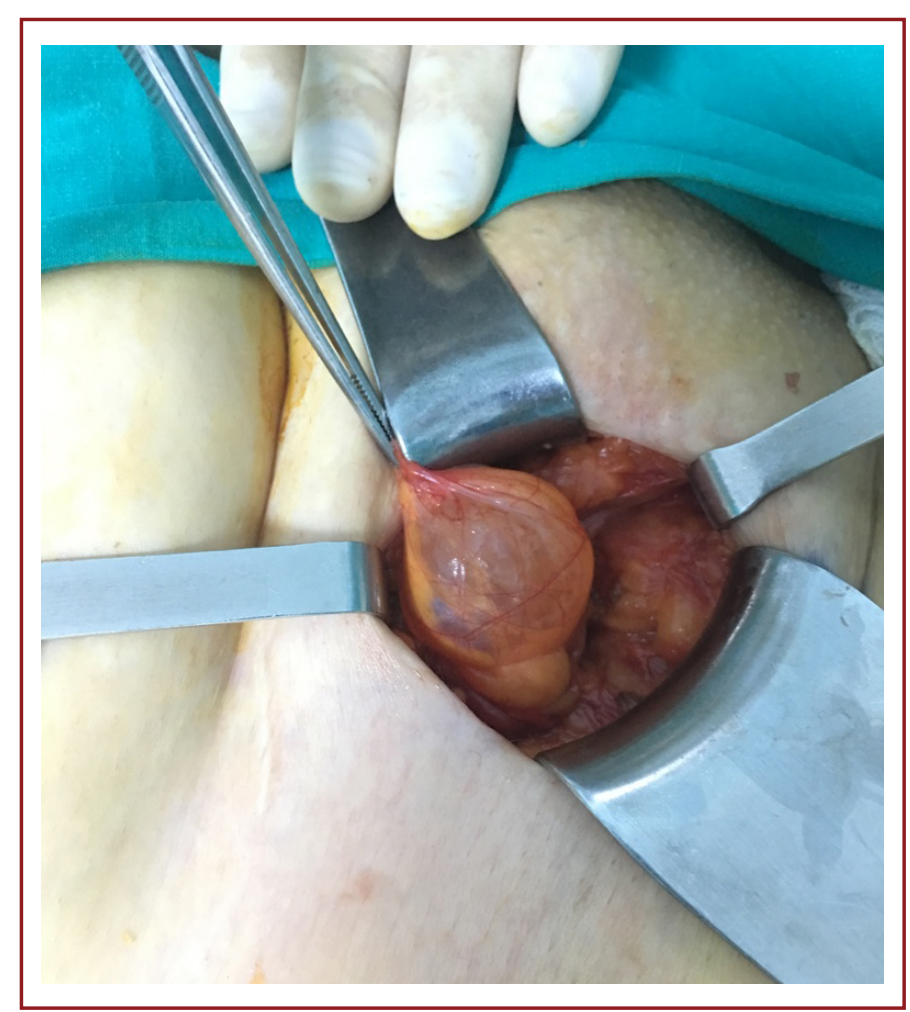

Figure 1. Hydrocele of the canal of Nuck.

the processus vaginalis causes indirect inguinal hernia or hydrocele of the canal of Nuck. Hydrocele of the canal of Nuck is a very rare condition, and Wei et al.,, ${ }^{[3]}$ have reported that the number of cases in the studies until 2002 was only 400.

Because of its presentation as a painless, translucent, and irreducible mass in the inguinal region, hydrocele of the canal of Nuck may be misdiagnosed as incarcerated inguinal hernia. Translummination is not always reliable due to the presence of the fascia of external oblique muscle. Differential diagnoses of inguinal swelling in a female patient include inguinal or femoral hernia, post-traumatic hematoma, lipoma, leiomyoma, sarcoma, hydrocele of the canal of Nuck, vascular aneurysms, endometriosis, or epidermal cyst ${ }^{[4]}$.

Clinical history and physical examination should be evaluated carefully. Imaging studies may be helpful to establish the diagnosis. High-resolution ultrasonography is the most commonly used procedure because it is relatively easy, accessible, and accurate. Magnetic resonance imaging can give information regarding the anatomic relation of the cystic lesion with adjacent structures ${ }^{[5]}$.

Surgical resection of the hydrocele and high ligation of the processus vaginalis, followed by histopathological examination, are the most accurate therapeutic approaches for definitive diagnosis. Cyst aspiration or injection of sclerosing agent into the cyst is not effective. Moreover, hydrocele of the canal of Nuck associated with inguinal hernia can be managed by laparoscopic approach ${ }^{[6]}$.

Hydrocele of the canal of Nuck is a very rare condition that should be considered as a differential diagnosis in females presenting with swelling in the inguinal region. Physical examination and imaging studies may be helpful for diagnosis. Surgical resection is the treatment of choice.

Informed Consent: Approval was obtained from the patients. Peer-review: Externally peer-reviewed.

Conflict of Interest: None declared.

Authorship Contributions: Concept: D.D.G.; Design: D.D.G.; Data Collection or Processing: M.G.; Analysis or Interpretation: M.G.; Literature Search: M.G.; Writing: M.G.

Financial Disclosure: The authors declared that this study received no financial support.

\section{References}

1. Khanna PC, Ponsky T, Zagol B, Lukish JR, Markle BM. Sonographic appearance of canal of Nuck hydrocele. Pediatr Radiol 2007;37:603-6. [CrossRef]

2. De Meulder F, Wojciechowski M, Hubens G, Ramet J. Female hydrocele of the canal of Nuck: a case report. Eur J Pediatr 2006;165:193-4. [CrossRef]

3. Wei BP, Castles L, Stewart KA. Hydrocele of the canal of Nuck. ANZ J Surg 2002;72:603-5. [CrossRef]

4. Poenaru D, Jacobs DA, Kamal I. Unusual findings in the inguinal canal: a report of four cases. Pediatr Surg Int 1999;15:515-6.

5. Park SJ, Lee HK, Hong HS, Kim HC, Kim DH, Park JS, et al. Hydrocele of the canal of Nuck in a girl: ultrasound and MR appearance. Br J Radiol 2004;77:243-4. [CrossRef]

6. Yen CF, Wang CJ, Lin SL, Chang PC, Lee CL, Soong YK. Laparoscopic closure of patent canal of Nuck for female indirect inguinal hernia. J Am Assoc Gynecol Laparosc 2001;8:143-6. [CrossRef] 